\title{
PERBAIKAN SISTEM PRODUKSI MINYAK ANGIN AROMATHERAPY MELALUI LEAN MANUFACTURING DI PT. US, JAWA BARAT
}

\author{
Rudy Indra Purnama, Zulfa Fitri Ikatrinasari \\ Program Magister Teknik Industri, Universitas Mercu Buana Gedung Tedja Buana Lt.4, \\ J1. Menteng Raya No.29 Jakarta Pusat Telp. (021) 3193-5454 Fax:(021) 3193-4474 \\ zulfafitri@gmail.com
}

\begin{abstract}
Abstrak
Industri farmasi sedang menghadapi persaingan yang meningkat, tekanan biaya dan kebutuhan untuk meningkatkan kinerja operasi manufakturnya. Lean manufacuring menawarkan metode, alat dan program heuristik untuk peningkatan produktivitas di bidang manufaktur. PT. US di Jawa Barat dapat meningkatkan kinerja perusahaannya melalui Lean manufacuring. Penelitian ini bertujuan meningkatkan produktivitas dengan mengidentifikasi dan menyeimbangkan proses kerja dan meneliti penyebab lamanya cycle time melalui value stream mapping. Penelitian ini menghasilkan penurunan cycle time dari 538,96 detik menjadi 445,68 detik, penurunan personel 14 orang, penurunan biaya operasional man power Rp.18,2 juta per bulan, dan menurunkan lead time dari 14,5 hari menjadi 11,5 hari.
\end{abstract}

Kata kunci: lean manufacturing, keseimbangan lini, peningkatan kapasitas, tact time, value stream mapping

\begin{abstract}
The pharmaceutical industry is facing increased competition, cost pressures and the need to improve the performance of its manufacturing operations. Lean manufacturing offer methods, tools and heuristic program for increasing productivity in manufacturing. PT. US in West Java, Indonesia can improve company performance with implementing Lean manufacturing. This study aims to improve productivity by identifying and balancing work and researching the causes of long cycle time with value stream mapping. This research resulted in a decrease cycle time of 538.96 seconds to 445.68 seconds, a decrease of 14 personnel, operating expenses decreased man power Rp.18, 2 million per month, and reduce the lead time of 14.5 days to 11.5 days .
\end{abstract}

Key words: lean manufacturing, line balancing, capacity building, tact time, value stream mapping

\section{PENDAHULUAN}

Di tengah ketidakstabilan perekonomian, perkembangan teknologi, dan peningkatan regulasi (GMP Good Manufacture Process / CPOB Cara Pembuatan Obat yang Baik) untuk persyaratan produk farmasi serta semakin tajamnya persaingan didunia industri farmasi, maka merupakan suatu keharusan bagi suatu industri farmasi untuk lebih meningkatkan fasilitas penunjang produksi dan tidak lupa untuk terus mencari improvement untuk mencapai efisiensi dalam kegiatan operasionalnya. PT. US merupakan perusahaan farmasi yang dituntut untuk dapat memperbaiki sistem yang berlangsung di perusahaan ini. FreshCare (FG121015) merupakan produk utama atau andalan untuk saat ini. Dimana untuk jumlah produksi menunjukkan $52 \%$ dibandingkan produk lain dan dilihat dari jumlah batch size menunjukkan $39 \%$ dibandingkan produk lain di bulan tersebut.

Lean Manufacturing menawarkan metode, alat, dan heuristik untuk efisiensi peningkatan di bidang manufaktur. Internal benchmarking direkomendasikan untuk menentukan efisiensi dan pelacakan perbaikan di bidang manufaktur farmasi (Lewis, 2006). Lean awalnya telah dibuat dan didefinisikan sebagai proses eliminasi atau mengurangi pemborosan (Womack and Jones, 1996). Toyota bersama dengan dukungan sebuah sistem untuk mengurangi atau menghilangkan pemborosan dan aktivtas yang tidak ada nilai tambah (NonValue Added) dari berbagai proses produksi. (Shing, 1989). 
Studi ini menyangkut identifikasi waste (pemborosan) yang terjadi dalam proses produksi dan menentukan fokus perbaikan. Hal penting yang perlu diketahui dalam mempelajari sistem produksi tersebut adalah bagaimana aliran proses produksinya, apa saja yang menjadi sumber pemborosan dan bagaimana cara menghilangkan atau meminimalkan pemborosan yang terjadi serta mempelajari kemungkinan dilakukannya perbaikan dalam sistem produksi sehingga diharapkan memberikan masukan yang tepat agar sistem berlangsung lebih baik.

Penelitian ini mempunyai tujuan secara umum untuk memberikan usulan peningkatan produktivitas dengan mengidentifikasi dan menyeimbangkan proses kerja yang terjadi dalam proses kerja di line produksi Minyak Angin Aromatherapy harus sama atau dibawah takt time. Meneliti dan mengkaji ulang apa saja hal yang menyebabkan lamanya cycle time produksi yang menyebabkan terjadinya pemborosan dengan adanya penumpukan material atau menganggurnya operator di line. Hal ini digambarkan melalui value stream mapping agar dapat mengurangi waktu tunggu, total cycle time, value added, manpower dan output/jam di departemen produksi.

\section{METODOLOGI PENELITIAN}

Lean Manufacturing merupakan metode optimal untuk memproduksi barang melalui peniadaan waste (pemborosan) dan penerapan flow (aliran), sebagai ganti batch dan antrian. Lean manufacturing adalah filosofi manajemen proses yang berasal dari Toyota Production System (TPS), yang terkenal karena menitikberatkan pada peniadaan seven waste dengan tujuan peningkatan kepuasan konsumen secara keseluruhan (Liker, 2004).

Karakteristik dari lean meliputi struktur lantai produksi yang aktif melakukan pemecahan masalah dengan penerapan kaizen dan continuous improvement, serta pelaksanaan lean manufacturing melalui tingkat inventory yang rendah, manajemen kualitas yang mengutamakan tindakan preventive (pencegahan) dibandingkan tindakan corrective (perbaikan), penggunaan pekerja yang sedikit, ukuran lot yang kecil serta penerapan konsep Just-in-Time (JIT), one-piece flow, jidoka dan heijunka. Dalam Toyota Production System (TPS) juga terdapat istilah Muda-Mura-Muri yang berarti (Liker, 2004).

Hubungan antara ketiga konsep ini membentuk garis lurus. Muri fokus pada persiapan dan perencanaan proses, atau pekerjaan yang bisa dihindari secara aktif melalui perencanaan, sedangkan Mura fokus pada implementasi dan peniadaan ketidakpastian dalam penjadwalan atau tingkat operasi, seperti kualitas dan volume, dan Muda ditemukan setelah proses berjalan dan berhubungan dengan reaktif. Ketiga konsep ini dapat ditemukan melalui variasi dalam hasil produksi. Tugas manajemen adalah untuk menemukan Muda dalam proses dan menghilangkan penyebab utamanya dengan mempertimbangkan hubungan Muri dan Mura yang terjadi dalam sistem.

Womack dan Jones (1996) mendefinisikan bahwa "Pemborosan merupakan setiap aktivitas manusia yang menggunakan sumber daya tetapi tidak menciptakan nilai tambah". Aktivitas tersebut seperti terjadinya kesalahan yang memerlukan perbaikan, produksi yang berlebihan sehingga terjadi kesalahan yang memerlukan perbaikan, produksi yang berlebihan sehingga terjadi penyimpanan (inventori), adanya pergerakan produk atau pekerja yang tak diperlukan dan sebagainya. Taiichi Ohno yang merupakan pimpinan Toyota yang mengidentifikasi tujuh jenis pemborosan, mengatakan bahwa pemborosan terjadi dimana-mana dan bisa ditemukan pemborosan lebih banyak lagi dari yang dibayangkan dalam setiap aktivitas (Womack dan Jones, 1996).

Dari pemikiran untuk mengatasi terjadinya pemborosan tersebut, maka lahirlah apa yang disebut Lean Thinking sebagai prinsip dalam Lean Manufacturing. Womack dan Jones (1996). Lean Enterprise Institute (2009) menyimpulkan bahwa Lean Thinking terdiri atas lima prinsip :

1. Mendefinisikan nilai dari sudut pandang pelanggan atau pemakai akhir.

2. Identifikasi aliran nilai(value stream). 
3. Membuat nilai mengalir lancar ke pelanggan tanpa gangguan.

4. Membuat mekanisme pull (value diberikan hanya jika diminta oleh pelanggan).

5. Lakukan langkah penyempurnaan secara terus menerus.

Konsep Lean Thinking ini diprakarsai oleh sistem produksi Toyota di Jepang. Lean dirintis di Jepang oleh Taichi Ohno dan Sensei Shigeo Shingo dimana implementasi dari konsep ini didasarkan pada 5 prinsip utama (Hines \& Taylor, 2000) yaitu: Specify value, Identify whole value stream, Flow, Pulled dan Perfection.

Dalam membuat pendekatan Lean Manufacturing maka pertama kali perlu membentuk tim yang bertujuan untuk mendesain, membangun dan menerapkan program Lean Manufacturing. Tim ini harus terdiri orang-orang dalam perusahaan yang bekerja full-time dalam mengerjakan program lean ini. Tim tersebut juga harus terdiri dari berbagai elemen dan memiliki pengalaman dan keahlian dibidangnya. Dalam tim dibuat peraturan bagaimana cara anggota tim berinteraksi satu sama lain sehingga komunikasi dapat terjalin (Feld, 2001)

Dalam tiap langkah-langkah di atas, banyak tools yang perlu digunakan untuk mencapai tujuan dari masing-masing langkah. Solusi haruslah melihat keseluruhan sistem, bukan hanya sebagian dari masalah, sehingga dapat memberikan pengaruh positif bagi keseluruhan sistem.

Beberapa perusahaan telah menerapkan Lean Manufacture, diantaranya(Wee \& Simon, 2009). : 1. Ford Motor Company, Taiwan, 2. General Motor (H.M. Wee dan Simon Wu,2009), 3. Chrysler (H.M. Wee dan Simon Wu,2009), dan 4. Toyota Motor Corporation (H.M. Wee dan Simon $\mathrm{Wu}, 2009)$.

Pendekatan Lean Manufacturing dalam penelitian ini menggunakan beberapa tahapan (Abdulmalek dan Rajgopal, 2007), yaitu:

1. Memilih produk atau famili produk tertentu sebagai target perbaikan.
2. Menggambarkan current state map yang merupakan gambaran bagaimana kondisi perusahaan saat ini untuk menentukan akar permasalahan yang terjadi pada perusahaan. Dalam tahapan ini, dilakukan penggambaran kondisi saat ini (current state mapping), analisis akar masalah (root cause analysis) dan menginformasikan manajemen terhadap apa yang terjadi. Pada tahap ini dapat menggunakan tools: Value Stream Mapping (VSM), Supplier-InputProcess-Output-Customer (SIPOC), Fishbone Diagram, dan lainnya.

3. Merancang future state map. Dalam tahap ini dilakukan analisa dan perancangan tindakan perbaikan yang akan dilaksanakan.

4. Tahapan implementasi. Tindakan implementasi dilakukan pada tahapan ini dari hasil perancangan yang telah dibuat sebelumnya.

\section{HASIL DAN PEMBAHASAN \\ Pemilihan produk sebagai target perbaikan}

Berdasarkan data produksi bulan maret 2012 di PT. US, menunjukkan bahwa produk FreshCare (FG121015) merupakan produk utama atau andalan untuk saat ini. Dimana untuk jumlah produksi menunjukkan $52 \%$ dibandingkan produk lain dan dilihat dari jumlah batch size menunjukkan $39 \%$ dibandingkan produk lain di bulan tersebut. Sehingga untuk selanjutnya proses produksi FreshCare yang akan dikaji untuk diperbaiki.

\section{Value Stream Mapping (Before)}

Aliran material dan informasi yang diperlukan dalam proses produksi line aromatherapy menggunakan tools peta aliran nilai saat ini atau value stream mapping current state. Peta aliran keadaan saat ini (VSM current state) memetakan kondisi yang terjadi dilapangan. Dari perusahaan menerima order dari buyer lalu diproses oleh departemen PPIC. Setelah jadwal produksi keluar dan bahan baku sudah ada di gudang maka proses weighing dimulai dari departemen PPIC. 


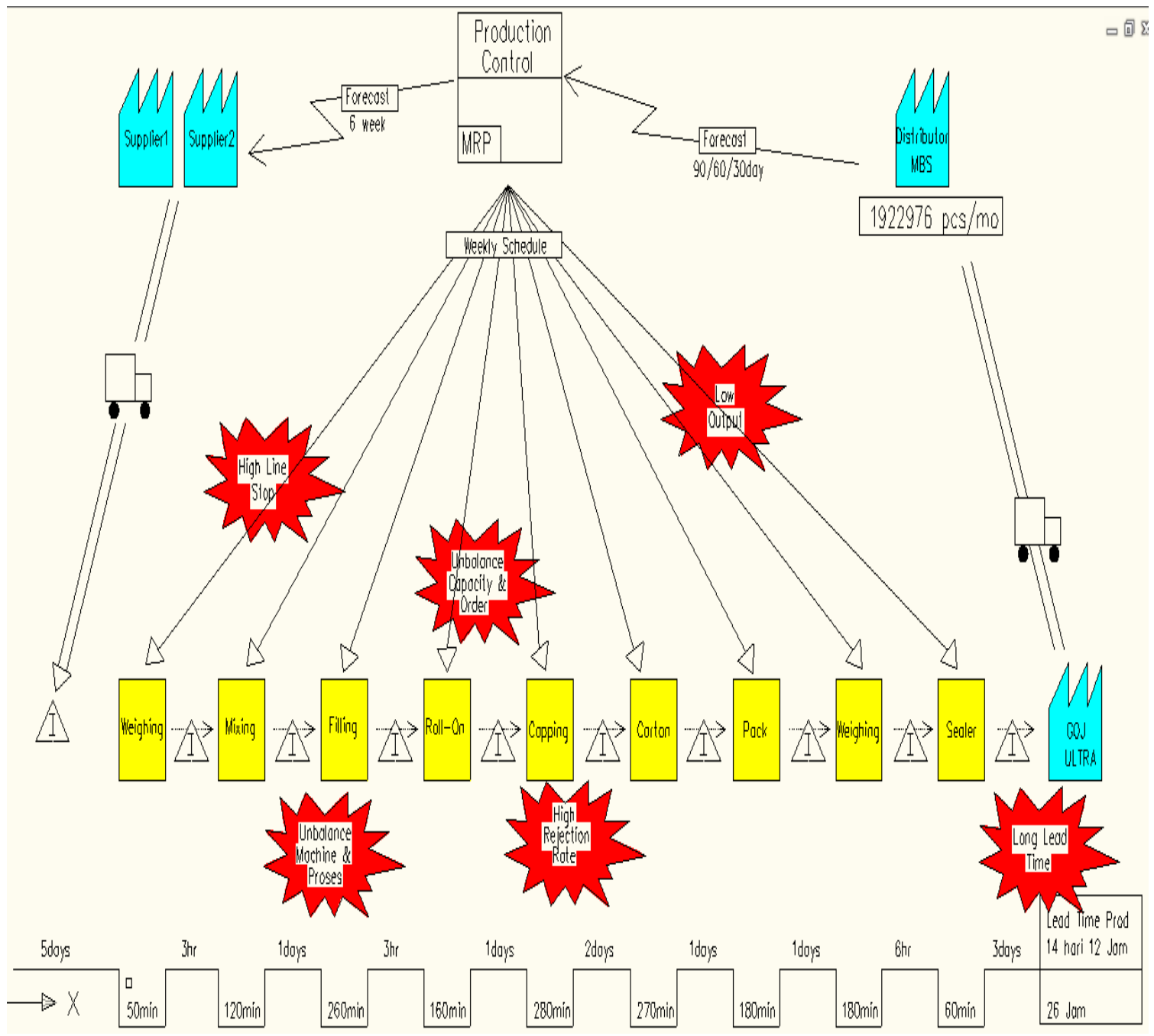

Gambar 1 Flow proses dan Jumlah tenaga kerja tiap proses

Permasalahan yang ditemukan dapat dilihat dari VSM Gambar 1. di atas antara lain :

1. High Line Stop

2. Unbalance Machine \& Process

3. Unbalance Capacity \& Order

4. High Rejection Rate

5. Low Output

6. Long Lead Time

Dilihat dari teori 7 Waste, keenam permasalahan di atas dapat dikelompokan menjadi dalam bagian pemborosan sebagai berikut :

1. Unappropriate processing $=$ Unbalance machine \& process $=$ Low Output

2. Defect (cacat produk) = High Rejection Rate
3. Transporting (transportasi) = Unbalance capacity \& order

4. Waiting (menunggu) $=$ High Line Stop Dari 4 pemborosan ini yang menyebabkan Lead Time proses tersebut menjadi lama.

Selanjutnya untuk mengetahui permasalahan lebih dalam, dilakukan analisa kondisi di lini produksi yang dilihat dari setiap aspeknya 4M+1E = Man, Machine, Methode, Material, Environment. Tiap-tiap aspek ditinjau dan dilihat apakah kondisi actual yang ada dilapangan sesuai dengan kondisi yang diharapkan. Hal ini dapat dilihat melalui Tabel 1. di bawah ini. 
Tabel 1 Analisis penyebab lead time produksi panjang

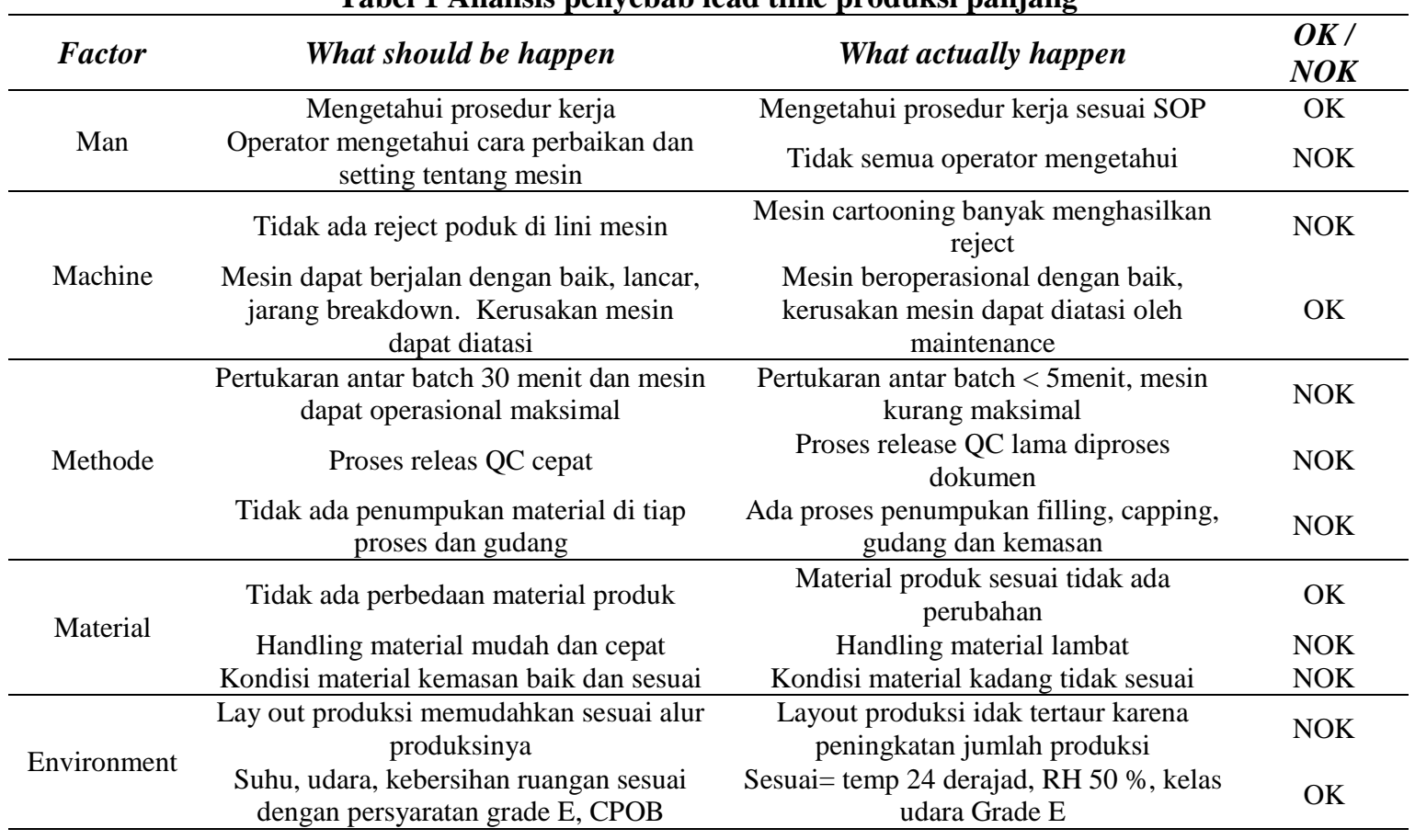

Tabel 2 Cycle Time Curent State

\begin{tabular}{lcccccccccc}
\hline Proses & Weighing & Mixing & Filling & Roll-On & Capping & Cartoning & Kemas & Weighing & Sealer & Total \\
\hline $\begin{array}{l}\text { Waktu } \\
\text { (min)/Batch }\end{array}$ & 50 & 120 & 260 & 160 & 280 & 270 & 180 & 180 & 60 & 1560 \\
Waktu (min)/day & 150 & 360 & 780 & 480 & 840 & 810 & 540 & 540 & 180 & 4680 \\
Waktu (sec)/day & 9000 & 21600 & 46800 & 28800 & 50400 & 48600 & 32400 & 32400 & 10800 & 280800 \\
Cycle Time & 17.27 & 41.46 & 89.83 & 55.28 & 96.74 & 93.28 & 62.19 & 62.19 & 20.73 \\
\hline
\end{tabular}

Tabel 3 Perhitungan Cycle Time tiap proses setelah perbaikan

\begin{tabular}{|c|c|c|c|c|c|c|c|c|}
\hline Proses & $\begin{array}{c}\text { Weighing \& } \\
\text { Mixing }\end{array}$ & Filling & Roll-On & Capping & Cartoning & Kemas & $\begin{array}{c}\text { Weighing \& } \\
\text { Sealer }\end{array}$ & Total \\
\hline $\begin{array}{l}\text { Waktu } \\
(\min ) / \text { Batch }\end{array}$ & 180 & 200 & 160 & 200 & 210 & 160 & 180 & 1290 \\
\hline Waktu (min)/day & 540 & 600 & 480 & 600 & 630 & 480 & 540 & 3870 \\
\hline Waktu (sec)/day & 32400 & 36000 & 28800 & 36000 & 37800 & 28800 & 32400 & 232200 \\
\hline
\end{tabular}

Usulan Perbaikan Sistem Produksi

1. Perbaikan production planning, unbalance machine $\&$ process

Sebelumnya penjadwalan produksi harian masih dilakukan secara berkelompok produk cairan / liquid dan kemasan. Hal ini mengakibatkan penyelesaian produksi tidak seimbang dan akan membuat output rendah. Usulannya yaitu memperbaiki jadwal produksi disesuaikan dengan kapasitas tiap prosesnya, yaitu antara mesin mixing, filling dan cartooning supaya tidak terjadi penumpukan di WIP atau mesin dan operator yang menganggur. Penggabungan beberapa proses produksi dengan memperhatikan cycle time dan beberapa improvement di tiap-tiap proses produksi yang akan dijelaskan selanjutnya.

Dapat dilihat cycle time tiap-tiap proses sudah stabil dan merata mendekati serta dibawah perhitungan takt time yaitu : 89.83 detik untuk tiap Master Boxnya. 


\section{Perbaikan alur proses produksi}

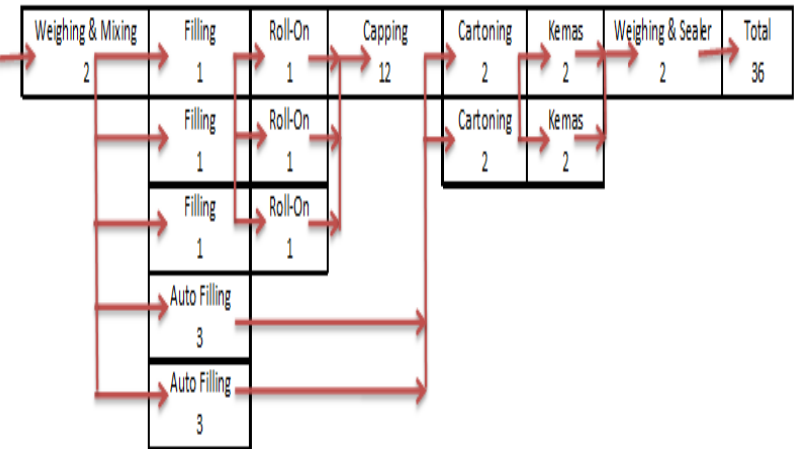

(a)

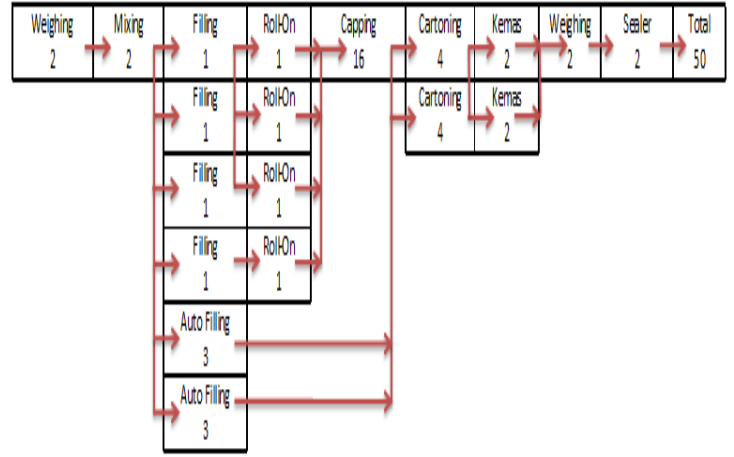

(b)

Gambar 2 Flow proses dan jumlah tenaga kerja tiap proses sebelum (a) dan sesudah (b) perbaikan

Penggabungan beberapa proses kerja untuk dilakukan untuk menyeimbangkan beban kerja. Tiaptiap proses yang mempunyai cycle time rendah dan berdekatan digabung menjadi satu rangkaian proses sehingga dapat mengurangi jumlah tenaga kerja. Dari gambar diatas dapat disimpulkan untuk proses produksinya akan didapatkan penghematan sekitar dari 14 tenaga kerja. Sebelumnya dapat dilihat jumlah tenaga kerja untuk line ini mencapai 50 orang. Dilakukan beberapa penggabungan pekerjaan antara lain untuk diawal proses weighing \& mixing serta di akhir proses weighing dan carton sealer dilakukan oleh operator yang sama.

Pengurangan juga terjadi karena ada improvement dari pembuatan mesin capping semi automatis, sekitar 16 orang menjadi 12 orang, serta optimalisasi mesin karena perbaikan bahan baku untuk mengurangi downtime total sekitar 4 orang. Total dari beberapa usulan diatas akan didapatkan pengurangan sekitar 14 tenaga kerja disbanding proses sebelumnya dengan tetap mengatur jadwal produksi yang sesuai yaitu sistem tarik.

\section{Perbaikan 5R dan transportasi / material handling}

Sebagian usulan telah dilakukan yaitu dengan membuat proses transportasi material lebih mudah dan jelas dengan cara membuat mixing tank dengan dengan roda dan dapat dibawa untuk pengisian dari tanki mixing ke tanki filling dengan transfer pump. Pembuatan lobang (Pass Box) memisahkan area packaging dengan gudang jadi untuk mesin karton sealer. Hal ini memudahkan untuk membawa material karton ke gudang dengan sekalian memproses sealer/isolatip pada karton.

Handling material pengemasan pun dilakukan usulan perbaikan dengan automatisasi proses dengan conveyor untuk menyalurkan produk dari proses ke pengemasan. Hal ini mengurangi adanya Inventory sementara / WIP. Tampak digambar atas sebelumnya penyimpanan produk setelah proses disimpan dulu di tong sebelum dikirim ke pengemasan. Setelah itu coba diperbaiki dengan bak terbuka dan selanjutnya dengan automatisasi dengan conveyor.

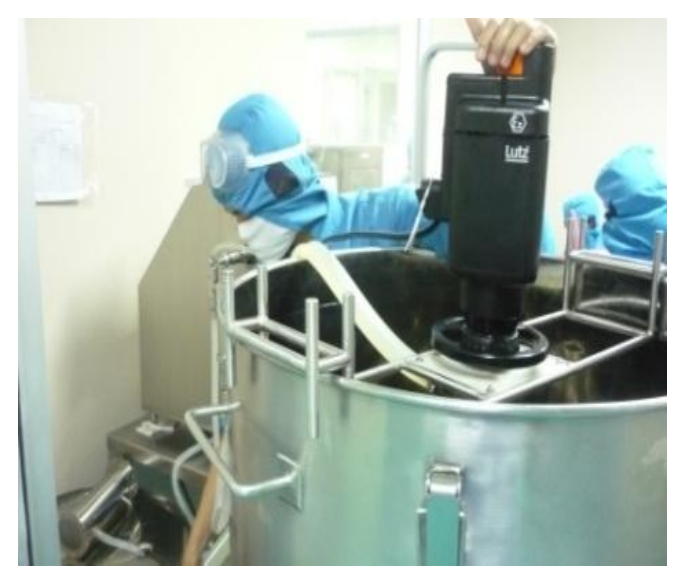

(a) 


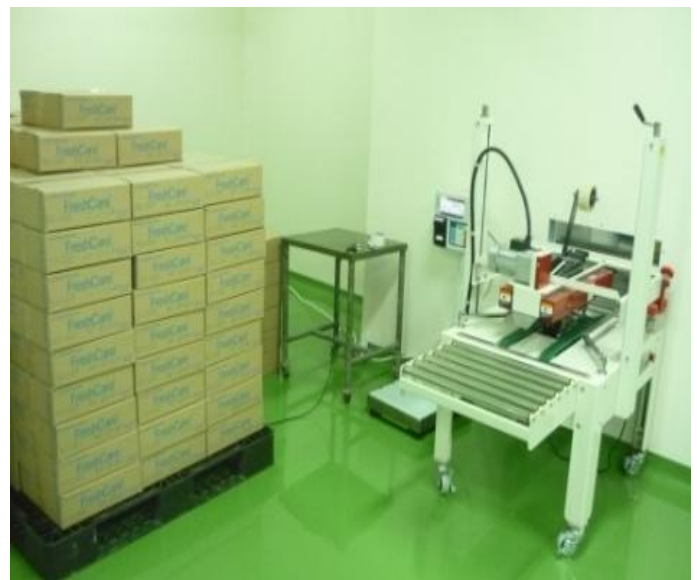

(b)

Gambar 3 Proses weighting dan carton sealer sebelum (a) dan sesudah (b) perbaikan

\section{Perbaikan High Rejection Rate}

Salah satu penyebab utama produk reject yaitu karena ada perbedaan material kemasan atau variasi. Variasi ukuran material ini disebabkan karena jumlah supplier lebih dari 1 (satu). Hal ini dilakukan oleh bagian pengadaan supaya tidak ada ketergantungan kepada satu supplier dan membuat perusahaan ini mempunyai bargaining power yang lebih untuk mengatur harga dari tiap-tiap supplier.

Variasi produk selain membuat reject tinggi juga mengakibatkan downtime mesin menjadi naik karena keperluan setting mesin untuk penyesuaian produk. Oleh karena itu dari semua supplier dibuatkan standart material yang sudah disepakati oleh team dari perusahaan ini dan dilakukan dengan melakukan evaluasi masing-masing part dari beberapa supplier. Membuat standart material utuk mengurangi variasi produk dari masing-masing supplier, terutama untuk material yang berhubungan dengan mesin (Botol, Roll-On, Capping, Carton dan Doos).

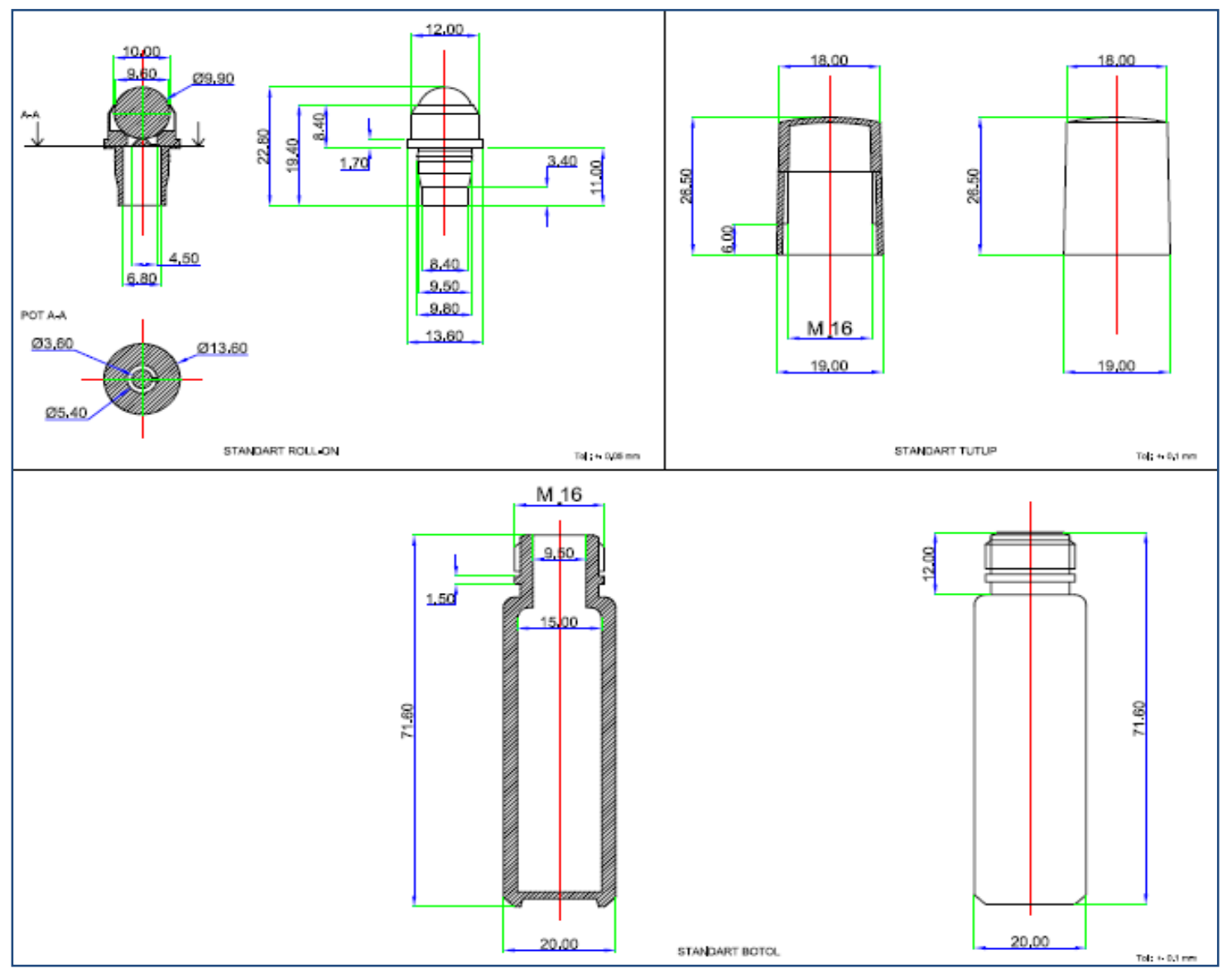

Gambar 4 Perbaikan standart material untuk botol, rool-on, capping. 
Untuk mengetahui kriteria defect produk, maka dibuatkan visual board untuk memudahkan bagi semua bagian baik QC, Produksi dan Packaging. Visual board ini kemudian harus disepakati bagi ketiga bagian ini supaya ada keseragaman pemikiran tentang defect produk agar tidak mengganggu proses selanjutnya karena pembiaran produk defect tersebut. Selain itu juga dilengkapi SOP untuk kriteria ini dan masin-masing bagian mempunyai PIC yang bertanggung jawab untuk menentukan kriteria defect tersebut.

\section{KESIMPULAN}

Berdasarkan analisis dan perbaikan proses produksi FreshCare melalui lean manufacturing, maka produkivitas akan meningkat. Hal ini dapat dilihat dari penurunan cycle time dari 538,96 detik menjadi 445,68 detik, penurunan biaya man power sebesar Rp. 18.200.000,- per bulan, dan penurunan lead time dari 14,5 hari menjadi 11,5 hari.

\section{DAFTAR PUSTAKA}

1. Abdulmalek, F.A., and Rajgopal, J., Analyzing the Benefits of Leasn Manufacturing and Value Stream Mapping via Simulation: A Process Sector Case Study. International Journal of Production Economics, vol. 107, 2007, pp 223-236.

2. Abuthakeer, S.S., Mohanram, P.V., and Kumar, G.M., . Activity Based Costing Value Stream Mapping, International Journal of Lean Thinking Volume 1, Issue 2, December 2010.

3. Farber, A., Schulze, U., and Wagner, K., Lean Comes To Pharma,

Pharmaceutical Executive, Nov 2009, 29,11; ABI/INFORM Research pg. 63.
4. Feld, W.M., Lean Manufacturing: Tools, Techniques, and How to Use

Them, St. Lucia Press, New York, 2001.

5. Geller, S., The Pharmaceutical Industry Looks to Reduce Waste by Getting Lean, Pharmaceutical Technology; Mar 2007; 31,3;ABI/INFORM Research.

6. Grewal, C., An initiative to implement lean manufacturing using value stream mapping in a small company, Int $J$. Manufacturing Technology and Management, Vol. 15, Nos. 3/4, 2008, pp.404-417.

7. Hines, P., and Taylor, D., Going Lean, Lean Enterprise Research Center, Cardiff Business School, 2000.

8. Lewis, N.A., A Tracking for Lean SolidDose Manufacturing, Pharmaceutical Technology; Oct 2006; 30, 10; ABI/INFORM Research

9. Liker, J.K., The Toyota Way, 14 Management Principles from The World's Greatest Manufacturer. McGraw-Hill Co., 2004.

10.Rother, M., and Shook, K., Learning to see, value stream mapping to add value and eliminate muda. The Lean Enterprise Institute Inc., Cambridge, Massachusetts, 2008.

11.Wee, H.M., and Simon Wu, Lean supply chain and its effect on product cost and quality: a case study on Ford Motor Company, Supply Chain Management: An International Journal, Vol. 14 Iss: 5, 2009, pp.335 - 341.

12.Yuniarti, A.M., Usulan Perbaikan Sistem Produksi Divisi Finishing pada Industri Sandal Jepit Dengan Menggunakan Pendekatan Lean Manufacturing, Thesis, Institut Teknologi Sepuluh November, 2010.

13.Womack, J.P \& jones, D.T., Lean Thinking: Banish waste and create wealth in your Corporation, Simon \& Schuster, New York, 1996. 